\title{
O JOGO COMO ORIENTADOR DA PRÁTICA PEDAGÓGICA NOS ANOS INICIAIS DO ENSINO FUNDAMENTAL
}

\author{
THE GAME AS GUIDING OF PEDAGOGICAL PRACTICE IN \\ THE EARLY YEARS OF ELEMENTARY SCHOOL \\ EL JUEGO COMO ORIENTADOR DE LA PRÁCTICA PEDAGÓGICA \\ EN LOS AÑOS INICIALES DE LA ENSEÑANZA FUNDAMENTAL
}

\begin{abstract}
Anemari Roesler Luersen Vieira Lopes
Professora Doutora da Universidade Federal de Santa Maria (UFSM) Santa Maria-RS, Brasil. anemari.lopes@gmail.com

Halana Garcez Borowsky

Doutora em Educação pela Universidade Federal de Santa Maria (UFSM) Santa Maria-RS, Brasil. halana.borowsky@gmail.com

Carine Daiana Binsfeld

Mestranda em Educação pelo Programa de Pós-Graduação em Educação da Universidade Federal de Santa Maria (UFSM) Santa Maria-RS, Brasil.

binsfeldcarine@gmail.com

Resumo: Este artigo objetiva discutir sobre o jogo como orientador da prática pedagógica do professor que ensina matemática nos anos iniciais do Ensino Fundamental, buscando compreender o papel dele na organização do ensino e no desenvolvimento da criança. Tendo a Teoria Histórico-Cultural, a Teoria da Atividade e a Atividade Orientadora de Ensino como fundamentos, assumimos uma concepção de educação na perspectiva da humanização e entendemos o jogo como uma atividade histórica e social, na qual o sujeito constrói suas relações sociais e desenvolve suas funções psicológicas superiores a partir de atividades. Nesse sentido, trazemos alguns apontamentos teóricos sobre o jogo e as ações do professor na organização do ensino, bem como uma situação de ensino voltada à aprendizagem do conceito de multiplicação. Como considerações, apontamos aspectos que permitem compreender o jogo como orientador da prática pedagógica: a intencionalidade pedagógica na prática docente por meio do jogo, em especial, para a organização do ensino de matemática; a contribuição do jogo para a atividade de ensino e de aprendizagem; e
\end{abstract} elementos importantes constituintes do jogo a ser desenvolvido.

Palavras-chave: Prática Pedagógica. Jogo. Matemática nos anos iniciais do Ensino Fundamental. Atividade Orientadora de Ensino.

\begin{abstract}
This paper aims to discuss about the game as a pedagogical practice guide of the teacher who teaches mathematics in the early years of Elementary School, seeking to understand its role in the organization of teaching and child development. Taking the Historical-Cultural Theory, the Activity Theory and the Teaching-Orienteering Activity as fundamentals, we assume a conception of education in the perspective of humanization and understand the game as a historical and social activity, which the subject builds his social relations and develops their superior psychological functions from activities. In this sense, we bring some theoretical notes about the game and the actions of the teacher in the organization of teaching, as well as a teaching situation focused on learning the concept of multiplication. As considerations, we point out aspects that allow to understand the game as guiding of the pedagogical practice: the pedagogical intentionality in the teaching practice through the game, in particular, for the organization of the teaching of mathematics; the contribution of the game to the teaching and learning activity; and important constituent elements of the game to be developed.
\end{abstract}

Keywords: Pedagogical Practice. Game. Mathematics in the early years of Elementary School. TeachingOrienteering Activity.

Resumen: Este artículo apunta la discusión sobre el juego como orientador de la práctica pedagógica del profesor que enseña Matemática en los años iniciales de la Enseñanza Fundamental, buscando comprender el papel de él en la organización de la enseñanza y en el desarrollo del niño. Llevando en cuenta la Teoría Histórico-Cultural, la Teoría de la Actividad y la Actividad Orientadora de Enseñanza como fundamentos, asumimos una concepción de educación en la perspectiva de la humanización y comprendemos el juego como una actividad histórica y social, la cual el sujeto 
construye sus relaciones sociales y desarrolla sus funciones psicológicas superiores por medio de actividades. En ese sentido, traemos algunos apuntamientos teóricos acerca del juego y de las acciones del profesor en la organización de la enseñanza, como también una situación de enseñanza en que el aprendizaje se vuelve al concepto de multiplicación. Como consideraciones, apuntamos aspectos que permiten comprender el juego como orientador de la práctica pedagógica: la intencionalidad pedagógica en la práctica docente por medio del juego, de forma especial para la organización de la enseñanza de matemática; la contribución del juego para la actividad de enseñanza y de aprendizaje; y elementos importantes constituyentes del juego a desarrollarse.

Palabras-clave: Práctica pedagógica. Juego. Matemática en los años iniciales de la Enseñanza Fundamental. Actividad orientadora de enseñanza.

\section{INTRODUÇÃO}

A formação, os conhecimentos e as práticas dos professores que ensinam matemática nos anos iniciais são, frequentemente, colocados à discussão como ineficientes; ora por falta de conhecimento matemático, ora pelas dificuldades apresentadas pelos estudantes durante o processo de escolarização ou, ainda, nos resultados insatisfatórios expressos nas avaliações em larga escala. Entendendo que aprender matemática nos primeiros anos de escolarização vai além de saber números e formas, de maneira técnica e mecânica, nosso grupo de pesquisa vem direcionando suas ações à compreensão das relações e à discussão das possibilidades que envolvem a tríade: formação do professor - prática pedagógica - aprendizagem do aluno.

Especificamente neste artigo objetivamos discutir sobre o jogo como orientador da prática pedagógica do professor que ensina matemática nos anos iniciais do Ensino Fundamental, buscando compreender o papel dele na organização do ensino e no desenvolvimento do estudante. Nossos argumentos e dados empíricos derivam de um projeto desenvolvido no âmbito do Grupo de Estudos e Pesquisas em Educação Matemática (GEPEMat), da Universidade Federal de Santa Maria (UFSM).

O grupo é composto por sujeitos de diferentes experiências e formações: acadêmicos em formação inicial dos cursos de licenciatura em Matemática, Pedagogia e Educação Especial; professores da Educação Básica e do Ensino Superior; e pós-graduandos do Mestrado e Doutorado em Educação e Educação Matemática. Como produto dessas vivências, atentamos para uma característica em especial, o compartilhamento das ações desenvolvidas.

O fundamento teórico principal de nossas ações e de nossas pesquisas ancora-se na Teoria Histórico-Cultural, em especial na Teoria da Atividade de Leontiev $(1983 ; 1978)$ e na Atividade Orientadora de Ensino (AOE) proposta por Moura $(1996$; 2010) que tem como uma de suas características a compreensão da importância do jogo na organização da prática pedagógica.

A partir dessa perspectiva, o movimento da pesquisa pretendeu compreender as potencialidades da intencionalidade pedagógica no trabalho educativo por meio do jogo, particularmente na aprendizagem matemática, entendendo-o como potencializador da apropriação da cultura humana e do desenvolvimento das funções psicológicas superiores.

Nesse sentido, trazemos, inicialmente, uma discussão sobre o jogo, a prática pedagógica e a organização do ensino de matemática e, em seguida, a Atividade Orientadora de Ensino como proposta para organização do ensino de matemática, fundamento teórico e metodológico adotado em nossas ações de investigação. Posteriormente trazemos o jogo na atividade de aprendizagem e na prática pedagógica, discutindo uma situação de aprendizagem extraída dos dados produzidos em nossa pesquisa. Finalmente, apontamos algumas considerações que consideramos relevantes sobre no jogo como orientador da prática pedagógica.

\section{JOGO, A PRÁTICA PEDAGÓGICA E A ORGANIZAÇÃO DO ENSINO DE MATEMÁTICA}

Ao iniciar um estudo sobre o ensino e a aprendizagem de matemática nos anos iniciais do Ensino Fundamental, por meio do jogo, faz-se necessário retomarmos nossa compreensão de que a matemática é um conhecimento cultural, elaborado a partir de necessidades humanas. Nesse sentido, apoiamo-nos na Teoria Histórico-Cultural, que tem como principal expoente Lev Semenovich Vigotski ${ }^{1}$. Essa escolha se deu justamente por acreditarmos que os sujeitos aprendem e se desenvolvem na relação com outros indivíduos mais experientes.

\footnotetext{
1 Considerando que a grafia do autor aparece de diferentes formas (Vygotski, Vygotsky, Vigotski, Vigotsky), ao referirmo-nos a sua obra utilizaremos Vigotski e ao fazer menção específica a uma obra do autor, será utilizada a grafia que consta na referida publicação.
} 
A criança, quando nasce, está desprovida de condições de sobrevivência, por isso necessita de um adulto para atender suas necessidades vitais iniciais. Essa condição de dependência é que inicia a sua interação com o outro, que, por sua vez, está inserido em uma cultura. Esse processo de interação é o início das primeiras comunicações e relações mediadas.

Consideramos que a Teoria Histórico-Cultural constituiu-se como um referencial importante, quando se pretende discutir sobre Educação numa perspectiva histórica e social, reconhecendo o desenvolvimento intelectual dos sujeitos, sua interação com outros e a formação de sua personalidade. É por esta razão que Vigotski passou a estudar formas superiores de comportamento, procurando entendê-las na relação do ser humano com o mundo.

Para Vigotskii (2014), todas as funções psicológicas aparecem duas vezes no desenvolvimento da criança: a primeira em atividades coletivas, ou seja, interpsíquicas; e, a segunda, em atividades individuais, como funções intrapsíquicas. Essa segunda atividade adquire intensidade na escola, quando ela começa a vivenciar situações organizadas intencionalmente pelo professor, que auxiliam na compreensão da realidade na qual está inserida. $E$ a criança, assim como os demais seres humanos, é movida por necessidades, as quais são supridas pelas atividades que executa que, por sua vez, podem auxiliar no desenvolvimento das funções psicológicas superiores.

É Leontiev (1988) que nos ajuda a compreender a atividade como os processos psicológicos caracterizados por "[...] aquilo a que o processo, como um todo, se dirige (seu objeto), coincidindo sempre com o objeto que estimula o sujeito a executar esta atividade, isto é, o motivo". (p. 68). Assim, para que uma ação se torne uma atividade, é necessário que o motivo que orienta essa ação coincida com o objeto a que ela se dirige. E, para que aconteça uma atividade, é necessário haver uma relação social, pois "a atividade de um ser humano é um sistema subordinado a um sistema de relações sociais e fora destas relações a atividade não tem existência alguma" (LEONTIEV, 2009, p. 56 , tradução nossa). ${ }^{2}$

Leontiev (2014) também destaca que, durante o período da vida de uma pessoa, ela passa por diferentes estágios de desenvolvimento psíquico, que se caracterizam na relação entre sujeito e realidade em que se encontra, e são orientados por um determinado tipo de atividade principal. E "o critério de transição de um estágio para o outro é precisamente a mudança do tipo principal de atividade na relação dominante da criança com a realidade" (LEONTIEV, 2014, p. 64), que seria aquela "cujo desenvolvimento governa as mudanças mais importantes nos processos psíquicos e nos traços psicológicos da personalidade da criança, em um certo estágio de seu desenvolvimento" (LEONTIEV, 2014, p. 65).

Mas o que seria o tipo principal de atividade? Para responder essa questão, baseando-nos no autor supracitado, delineamos três aspectos fundamentais que a caracterizam:

- é uma atividade em que podem surgir dentro dela outras atividades;

- é aquela em que os processos mentais são organizados e ganham forma;

- é aquela em que há mudanças psicológicas de personalidade, que podem ser observadas em um determinado período de desenvolvimento.

A ideia de Leontiev sobre o conceito de atividade principal leva-nos a entender que, em cada fase de desenvolvimento de uma pessoa, ela domina e compreende a realidade de uma forma diferente. E essa atividade se altera, conforme a fase em que a pessoa se encontra. Para ele, são três atividades principais na vida do ser humano: o jogo, o estudo e o trabalho.

O jogo seria a atividade principal da criança em idade pré-escolar, no qual ela busca compreender o mundo a partir de ações realizadas com os adultos, permeadas pela ludicidade. E quando, em um período no estágio de desenvolvimento da criança, ela se dá conta de que suas capacidades se ampliaram, procurando um novo conteúdo nas relações que estabelece, aparece a necessidade de desenvolver o pensamento teórico e acontece uma mudança de atividade principal, ou seja, a atividade dominante passa a ser o estudo. Assim como nos outros estágios, a partir da atividade de estudo, com a mudança das relações, o sujeito começa a perceber que tem uma responsabilidade social com seu coletivo, tornando o trabalho sua atividade principal. O trabalho é a atividade do adulto e, em relação ao trabalho do professor, entendemos que está relacionada à organização intencional do ensino, no caso deste estudo, do ensino de matemática nos anos iniciais do Ensino Fundamental.

2 Texto original: "la actividad de un ser humano es un sistema subordinado a un sistema de relaciones sociales y fuera de estas relaciones la actividad no tiene existencia alguna" (LEONTIEV, 2009, p. 56). 
Cabem aqui esclarecermos sobre a compreensão do jogo e a atividade do professor a partir de nossa perspectiva teórica.

Nascimento, Araújo e Miguéis (2009) destacam que as principais correntes teóricas sobre o desenvolvimento humano abordam sobre o jogo, e esses estudos em comum consideram a sua relação com o desenvolvimento humano. A teoria histórico-cultural parte da tese de que o desenvolvimento do psiquismo é determinado pelas relações mediadas social e culturalmente. Nesse sentido, o jogo é considerado como "aquela atividade que melhor realiza a relação criança/mundo, no sentido de permitir a máxima apropriação das produções culturais historicamente elaboradas". (NASCIMENTO, ARAÚJO; MIGUÉIS, 2009, p.296).

Especificamente, em nosso trabalho, não estaremos nos referindo ao jogo como atividade principal da criança, já que estamos voltados aos anos iniciais do Ensino Fundamental, mas nossa compreensão corrobora com o que nos apresentam as autoras citadas, e ressaltamos que o jogo, quando usado como instrumento pedagógico, deve ter por objetivo não somente o despertar do aspecto lúdico, como normalmente é adotado, mas revelar as relações humanas nele presentes, de modo que o aluno possa delas se apropriar. Com isso não queremos de forma nenhuma desconsiderar a ludicidade, que consideramos um aspecto importante, mas compreender o lúdico "como uma forma específica do homem se relacionar com o mundo, forma específica de efetivar as suas relações fundamentais de objetivação e apropriação e, assim, poder desenvolver-se culturalmente." (NASCIMENTO, ARAÚJO; MIGUÉIS, 2009, p.296).

Essa compreensão torna-se importante na prática pedagógica nos anos iniciais, principalmente, quando nos voltamos à atividade principal do professor, que é o ensino, ou seja, ele é o responsável por organizar suas ações de modo que seus alunos se apropriem dos conhecimentos historicamente elaborados pela humanidade. Para que isso aconteça, defendemos a relevância do planejamento como um elemento que permite ter o domínio da sua prática, mesmo que provisório, já que ele se desenvolve no movimento da sala de aula e, assim, constantemente se reconfigura.

$\mathrm{O}$ ato de planejar implica, necessariamente, a intencionalidade pedagógica. Quando o professor assume postura de responsável em trabalhar o conhecimento matemático com seu aluno, é preciso que ele faça isso com uma intenção: a apropriação de conhecimentos por parte desse aluno. O planejamento é um dos principais instrumentos da ação pedagógica e, em sua elaboração, é importante que o professor tenha muito claras suas intenções, os recursos, a forma de registro e de avaliação adotada.

O objetivo do professor é fazer com que o seu aluno se aproprie da cultura humana mais elaborada, de modo que ele tenha condições de desenvolver suas máximas potencialidades, o que não acontece de forma espontânea nas suas relações cotidianas. Nessa perspectiva, a apropriação do conhecimento matemático - entendido como parte da cultura humana mais elaborada - não se dá somente no cotidiano social. Entendemos a escola como o espaço especial para apropriação desses conhecimentos, a partir da intencionalidade do professor, expressa em seu planejamento e, por isso, destacamos quatros pontos fundamentais na organização do ensino: estudo, organização das ações, registro, avaliação.

Os motivos do professor ensinar determinado conteúdo devem coincidir com o objeto da atividade de ensino, ou seja, a aprendizagem do aluno. Desse modo, o professor também é protagonista na relação entre ensino e aprendizagem, desempenhando um papel fundamental no processo da apropriação de conhecimentos. Assim, quando trazemos como um dos elementos do planejamento o estudo, enfatizamos a importância de o professor estudar e buscar compreender os conceitos matemáticos, bem como qual foi a necessidade humana que levou à sua criação. Por isso, as ações devem estar intencionalmente organizadas com esse propósito, mobilizando os alunos a aprenderem a partir de uma necessidade similar àquela que a humanidade sentiu ao criar o conceito em questão. É esse movimento que pode levar à apropriação do processo lógico-histórico (KOPNIN, 1978) da caracterização do conceito matemático, no qual o histórico reflete o movimento de mudança do conceito e o lógico a organização do pensamento a partir do histórico.

Também apontamos o registro como um elemento importante. Esse registro pode ser operacionalizado em duas dimensões: o registro do professor, no qual ele fará anotações sobre as hipóteses de seus alunos e suas aprendizagens; e o registro do aluno, no qual ele pode registrar o que vem estudando, a fim de organizar seu pensamento, no movimento de apropriação do conceito estudado, e de demonstrar suas aprendizagens. 
Com o estudo, a organização das ações e o registro, passamos para o próximo elemento: a avaliação. Ao avaliar, o professor estará repensando sobre sua prática, sobre as estratégias utilizadas e a aprendizagem de seus alunos, tendo a possibilidade de aperfeiçoá-la, aprendendo sobre a docência a partir de sua própria prática. E os estudantes, ao fazerem esse mesmo processo de avaliação, irão trocar conhecimentos e aprendizagens, sendo protagonistas desse processo e formando novas funções psíquicas.

Entendemos que a unidade desses quatro elementos caracterizam o ensino intencionalmente organizado, que pode levar à aprendizagem e promover o desenvolvimento cognitivo do estudante, na medida em que pode adiantar-se ao desenvolvimento, como preconiza Vigotski. Nessa direção, defendemos a Atividade Orientadora de Ensino (AOE), elaborada por Moura (1996; 2010), como uma proposta teórica-metodológica para organização do ensino, que se configura como teórica pelos seus pressupostos na Teoria Histórico-Cultural e na Teoria da Atividade, e como metodológica por apresentar instrumentos para a organização do ensino, a partir da relação entre conceitos espontâneos e conceitos científicos.

Alguns elementos desta teoria têm contribuído para melhor compreendermos a aprendizagem dos estudantes e dos professores e a organização do ensino, principalmente na sua relação com o processo de humanização na escola, compreendido como a apropriação da cultura humana por meio do trabalho do professor. A seguir, trataremos especificamente sobre a organização do ensino a partir da $\mathrm{AOE}$, que fundamentou as situações de ensino por nós desenvolvidas.

\section{A ATIVIDADE ORIENTADORA DE ENSINO COMO PROPOSTA PARA ORGANIZAÇÃO DO ENSINO DE MATEMÁTICA}

Há algum tempo educadores que ensinam matemática vem apresentando e discutindo diferentes metodologias e instrumentos para o ensino de matemática, particularmente nos anos iniciais do Ensino Fundamental, buscando romper com aquele considerado tradicional, pautado no exercício e na memorização de conteúdos e fórmulas. Contudo, embora sejam perceptíveis os avanços na área, essa forma de ensinar matemática, considerando-a difícil para quem ensina e para quem aprende, ainda está presente em muitas realidades escolares.

É por este motivo, juntamente com a compreensão da importância do jogo nas relações da criança com seus pares e no desenvolvimento de sua personalidade, que se torna importante discutirmos sobre a organização do ensino de matemática que considere a relação com o outro e os conhecimentos científicos matemáticos, para a ampliação do desenvolvimento mental do sujeito. Essa concepção nos leva a propor um ensino na perspectiva da humanização, no sentido de contribuir para o desenvolvimento intelectual do sujeito, de modo que ele desenvolva, ao máximo, suas funções psicológicas superiores.

Conforme ressaltamos, no decorrer deste texto, entendemos que a docência é o trabalho do professor e organizar o ensino, com intencionalidade, é uma de suas responsabilidades para oportunizar aos seus alunos a apropriação da cultura mais elaborada. Ou seja, aquela específica da escola, que envolve conceitos científicos, visando o desenvolvimento do pensamento teórico.

Tomando como premissa os estudos da teoria histórico-cultural, que traz a escola como um espaço privilegiado para os sujeitos apropriarem-se dos conhecimentos historicamente elaborados, e também a teoria da atividade, a qual entende que é por meio da atividade que o ser humano desenvolve seu pensamento, Moura (1996; 2010) propõe a Atividade Orientadora de Ensino - AOE. Nessa perspectiva,

a atividade é orientadora porque o professor parte do pressuposto de que o resultado final da aprendizagem é fruto das ações negociadas e tem consciência de que não domina o conjunto de fenômenos da classe. Por isso elege uma orientação geral que possibilita saber a direção a ser seguida para um ensino construtivo. (MOURA, 1996, p. 19).

Nessa proposta, professor e aluno têm papéis bem definidos e cabe ao professor a intencionalidade do trabalho desenvolvido na escola, cujo objetivo é a apropriação lógico-histórica, por parte do aluno, de um conceito, no caso de nossa pesquisa, de matemática. Quando entendemos a escola desta forma, como o lugar social para o sujeito se apropriar de conhecimentos produzidos 
ao longo da história humana, passamos "necessariamente por assumir que a ação do professor deve estar organizada intencionalmente para este fim" (MOURA et al, 2010 p. 212).

A organização do ensino, através da AOE, busca permitir ao estudante apropriar-se do conhecimento matemático, considerando o processo lógico e histórico ${ }^{3}$ que a humanidade vivenciou ao elaborar o conceito. A característica de orientadora está relacionada à interação entre aluno e professor, sendo atividade do professor estudar e planejar intencionalmente o ensino, de modo que o aluno se aproprie do conceito estudado de uma forma lúdica e prazerosa. A AOE é aquela atividade que

[...] respeita os diferentes níveis dos indivíduos e que define um objetivo de formação como problema coletivo é o que chamamos de atividade orientadora de ensino. Ela orienta um conjunto de ações em sala de aula a partir de objetivos, conteúdos e estratégias de ensino negociado e definido por um projeto pedagógico. Contém elementos que permitem à criança apropriar-se do conhecimento como um problema. E isto significa assumir $\mathrm{o}$ ato de aprender como significativo tanto do ponto de vista psicológico, quanto de sua utilidade. (MOURA, 1996, p. 32).

A figura a seguir sintetiza as ideias em relação a essa proposta.

Figura 1 - Organização do Ensino de Matemática

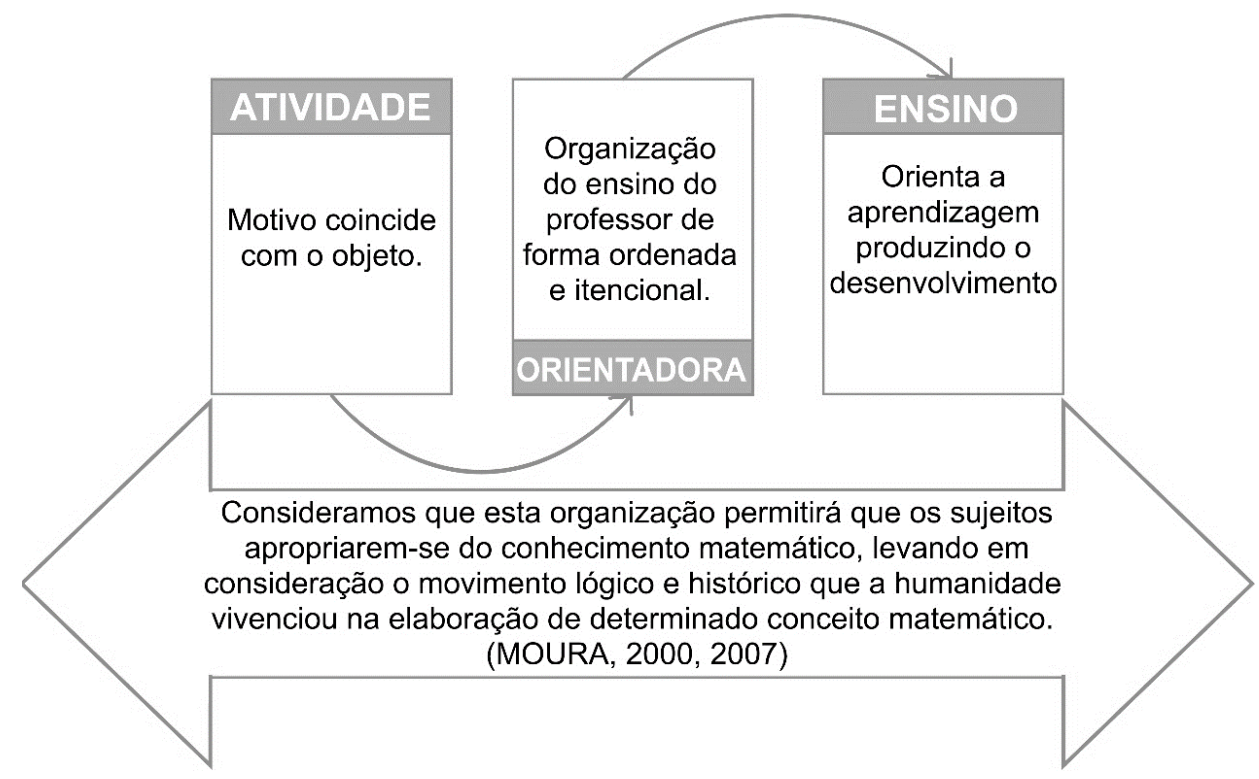

Fonte: sistematização das autoras a partir de Moura $(2000,2007)$.

Como já mencionado, a AOE configura-se como um modo de organização do ensino de matemática, da qual nos reportamos a três elementos que orientam a ação do professor no planejamento das situações que vai desenvolver, são eles: a síntese histórica do conceito, a situação desencadeadora de aprendizagem e a sintese da solução coletiva.

A síntese histórica do conceito explicita a necessidade que a humanidade vivenciou na elaboração de um conceito matemático que precisa ser compreendido pelo professor na medida em que deverá estar expressa na situação desencadeadora de aprendizagem (SDA) a ser elaborada para os alunos. A SDA compreende uma situação problema que desafie o estudante a solucionála, a partir de uma necessidade em apropriar-se do conceito matemático. Nas palavras de Moura (2010, p. 223), deve, "contemplar a gênese do conceito, ou seja, a sua essência; ela deve explicitar a necessidade que levou a humanidade a construção do referido conceito". A síntese da solução coletiva refere-se à elaboração dos estudantes de uma solução para o problema proposto pela situação desencadeadora de aprendizagem, com uma busca coletiva pela resposta "matematicamente correta" e "se dá quando aos indivíduos são proporcionadas situações que exigem o compartilhamento das ações para a resolução de uma determinada situação que surge em certo contexto." (MOURA,

\footnotetext{
3 Entendemos o par lógico-histórico, a partir de Davidov (1988), como os conhecimentos que serão apropriados pelos estudantes, ou seja, a característica de histórico está relacionada ao surgimento e ao desenvolvimento do conhecimento e, o lógico, é o modo como o pensamento se realiza na compreensão do histórico.
} 
2010 , p. 106). Esse momento requer do professor uma atenção especial, para mediar todas as hipóteses e promover questionamentos delas para, então, os estudantes elaborarem uma síntese comum compreendida pelo grupo.

Ao pensar na situação desencadeadora de aprendizagem, o professor pode organizar o ensino, utilizando diferentes estratégias, como por exemplo: o jogo, a história virtual ou uma situação emergente do cotidiano. Para entendermos melhor:

- o jogo precisa desencadear uma busca pela apropriação do conceito, sendo que pode ser criado pelo professor, readaptado ou, até mesmo, um jogo que já existe no meio cultural da criança, desde que a matemática esteja presente;

- a história virtual do conceito é uma situação problema apresentada em um enredo com personagens infantis em histórias, lendas ou contos, de modo que se configure como desencadeadora de aprendizagem, idealizada justamente para colocar o estudante em uma situação de aprendizagem. Segundo Lopes e Vaz (2014), é denominada virtual por "não estar diretamente relacionada à realidade, embora ela represente uma situação problema real vivenciada pela humanidade". (p. 08);

- a situação emergente do cotidiano, como o nome já diz, configura-se como uma situação que surge do dia a dia da sala de aula, da comunidade em que vivem, de momentos da atualidade, de situações problemas que partem dos estudantes e de suas relações com seu meio.

Estas três possibilidades permitem-nos compreender modos de organizar o ensino nessa perspectiva, sendo que no presente estudo, olharemos em especial para o jogo como orientador da prática pedagógica, na perspectiva teórica que explicitamos. Por isso, no tópico a seguir, trataremos especificamente do jogo e seu papel no desenvolvimento da criança e na organização do ensino.

\section{JOGO NA ATIVIDADE DE APRENDIZAGEM E NA PRÁTICA PEDAGÓGICA}

Com base nos estudos da Teoria Histórico-Cultural, destacamos o jogo como uma atividade histórica e social. O trabalho é uma atividade específica do adulto e o jogo é uma atividade específica da criança, apesar de permanecer ao longo da vida de formas distintas, como nos explicam Nascimento, Araújo e Miguéis (2009, p.300):

Na contemporaneidade, as atividades lúdicas mantêm a sua importância como atividades que permitem a explicitação das relações de apropriação e objetivação, sendo, apesar disso, atividades secundárias para os adultos, mas essenciais para as crianças.

É por meio do jogo e da relação com o outro que a criança estará mostrando sua compreensão sobre a cultura e a realidade que a cerca, além disso, é um modo dela se apropriar dos conhecimentos desta cultura. O mundo adulto não é acessível à criança, ou seja, ela não pode participar ativamente das atividades dos adultos. Para compreender esse espaço (do adulto), a criança inicialmente imita suas ações a partir de jogos de papéis e faz de conta, a fim de compreendê-lo, pois sente necessidade de compreender o mundo do adulto e suas relações, daí a importância do papel do jogo no desenvolvimento infantil. Desse modo, "o jogo é um papel em desenvolvimento, a parte do papel orientada para o futuro, o que dele resulta; as regras são escolas de vontade (o trabalho do escolar); e a situação fictícia é o caminho da abstração" (ELKONIN, 1988, p. 4).

A partir dessa necessidade de compreender o mundo, a atividade da criança pré-escolar é o jogo de papéis, também denominado jogo protagonizado. O jogo de papéis pode ser considerado um tipo particular de atividade em que a criança começa a experenciar a realidade do mundo adulto no qual está inserida, ou seja, começa a brincar, por exemplo, de "mamãe", demonstrando o que a figura materna representa em sua vida e o modo como ela vem compreendendo este papel. Nesta fase da vida da criança, a relação que ela desempenha no jogo tem características mais egocêntricas e o outro ainda não é visto no ato de jogar. Embora a criança vivencie um momento de interpretação fictício, de representação, esse momento está diretamente relacionado à realidade concreta, pois representa uma situação real.

Assim, podemos entender o jogo como uma atividade social, pois é a partir dele que a criança começa a compreender a sociedade (ELKONIN, 1988). À medida que a criança vai se desenvolvendo, o papel que ela desempenha no jogo vai se alterando, assim como as relações que se estabelecem 
com o outro, pois ela começa a passar por um estágio de desenvolvimento mais elevado, mais complexo. Aqui, o jogo de papéis, que até pouco tempo poderia satisfazer suas necessidades, se altera, pois, a criança exige

O domínio de uma área mais ampla da realidade [...] área esta que não é diretamente acessível a ela - só pode, portanto, ser obtido em um jogo. Por causa disso, o jogo adquire uma forma muito rara, qualitativamente diferente da forma do brinquedo que observamos na idade pré-escolar, e neste mais alto estágio do desenvolvimento mental da criança, o jogo agora torna-se verdadeiramente a atividade principal (LEONTIEV, 2014, p. 122).

Dessa maneira, o jogo começa a desempenhar um papel extremamente importante, pois os sentidos que a criança busca compreender da realidade que está inserida se alteram, exigindo novos modos de compreender esta realidade, que agora passa a ser por meio do jogo. Como já referimos anteriormente, Leontiev (2014) coloca que o jogo é a atividade principal do sujeito em estágio pré-escolar, contudo, como o estágio de desenvolvimento nem sempre coincide com a idade cronológica e com o período de escolarização da criança, mesmo quando ela está nos anos iniciais, o jogo pode ser sua atividade principal. Além disso, mesmo não sendo a atividade principal, pode se constituir em uma atividade para a criança, na perspectiva de Leontiev, contribuindo com o seu desenvolvimento independentemente da idade cronológica ou do ano de escolarização.

A partir dessa compreensão do jogo como um elemento importante no desenvolvimento do sujeito, particularmente em idade escolar, é que defendemos seu uso no âmbito da educação, como uma possibilidade de organização do ensino e, nessa perspectiva, orientador da prática pedagógica.

Como mencionado anteriormente, conforme a criança se desenvolve o papel social que ela desempenha se altera. Ao passar do jogo de papéis para outros tipos de jogos, as relações que ela estabelece com os outros e seus interesses também se modificam. Nesse sentido, Elkonin (1988) ajuda-nos a compreender que cada ação que a criança irá realizar possui uma continuação lógica relacionada com outra ação que poderá substituir a primeira. Ou seja, os objetos, os brinquedos e o ambiente constituem-se como significativos durante o jogo, pois as crianças jogam juntas e cada ação desenvolvida por uma delas está relacionada à ação da outra. Assim, a criança começa a compreender a importância do outro no jogo, e nessa troca de significados, ela começa a atribuir sentido ao que está estudando.

Mas trazer o jogo para a sala de aula, como possibilidade de organização do ensino, constituise como um desafio para os professores, uma vez que exige a intencionalidade pedagógica. As ações do professor no contexto do jogo são determinantes, pois o jogo, por si só, não proporciona a aprendizagem e o desenvolvimento e nem leva a criança a compreender a realidade que a cerca. Antes, sim, são as relações que ela estabelece ao jogar, orientadas pelo professor, que lhe permitirão se apropriar do conteúdo contido no jogo. E esse movimento, de propor o jogo a partir da orientação do professor, pode ser evidenciado quando o professor organiza a situação desencadeadora de aprendizagem com o jogo, levando como premissa, os pressupostos da AOE.

Ressaltamos, ainda, a importância do adulto ou de outra criança mais experiente é fundamental. $\mathrm{Na}$ interação com o outro, a criança estabelecerá uma troca de experiência e de conhecimentos, poderá criar hipóteses sobre determinadas situações, criar regras, problematizar e interagir com sua cultura. Desse modo, a criança aprende e se desenvolve em uma situação com o jogo.

Moura (1997) auxilia-nos a entender que o jogo é capaz de promover o desenvolvimento, quando nele está impregnada a intencionalidade de aprendizagem. Isso ocorre porque as crianças, quando jogam, começam a se relacionar com regras que lhe permitem compreender diversos conhecimentos relacionados socialmente, e isso irá lhes permitir novas qualidades psíquicas na aprendizagem de conhecimentos futuros.

Pensar o jogo dentro do espaço pedagógico requer cuidado e atenção. A criança cria situações e regras muito próprias, daí a necessidade do professor considerar que estará, também, lidando com diferentes sentimentos e conhecimentos espontâneos. Ou seja, conforme salienta Moura (1992, p. 47), "ao optar pelo jogo como estratégia de ensino, o professor o faz com uma intenção: propiciar a aprendizagem". Quando assume o jogo com esse propósito, a intencionalidade acrescida à prática pedagógica é determinante para que o jogo cumpra o objetivo de permitir a apreensão de determinado conceito ou habilidade. 
Sendo assim, a opção por organizar o ensino de determinado conteúdo matemático, por meio de um jogo, implica que o conceito deste conteúdo estará implícito no jogo e poderá ser apropriado pela criança nas relações que ela estabelecer durante esse jogo. Assim, será orientador da prática pedagógica, quando o professor organizar o seu ensino na perspectiva de que as ações desenvolvidas pelas crianças lhe permitam acender a um grau mais elevado do conhecimento que já tinha, sendo esse movimento o objetivo final do professor.

[...] desenvolver o intelecto significa desenvolver muitas capacidades específicas e independentes e formar muitos hábitos específicos, já que a atividade de cada capacidade depende do material sobre o qual essa capacidade opera (VYGOTSKY, 2005, p. 31).

Reiteramos que se a intencionalidade do professor volta-se para a organização do ensino visando a aprendizagem de um conceito matemático, esse deve estar claramente expresso nas possíveis situações que o jogo proporcionará para o aluno e que serão resolvidas a partir de um modo específico, ou seja, por meio de um conhecimento matemático.

Quando a organização do ensino, por meio de um jogo, permitir ao aluno colocar-se em um movimento de aproximação com os conteúdos estudados na escola, também estará proporcionando que os estudantes desenvolvem novas estruturas cognitivas. Nesse sentido, no papel de organizador do ensino, o professor irá sistematizar o jogo como uma atividade que estimule a necessidade de aprendizagem do educando. Assim, o jogo poderá constituir-se como formador para o aluno e também para o professor, pois os erros e os acertos dos alunos poderão indicar possíveis encaminhamentos para tornar sua prática pedagógica de melhor qualidade.

Como mencionado anteriormente, ao organizar o ensino através de um jogo, a partir dos pressupostos da AOE, o professor pode pensar esse movimento de duas formas: utilizando um jogo já existente, desde que a essência do conceito matemático a ser trabalhado esteja presente; ou criar um jogo em que a essência do conceito se faça presente no seu desenvolvimento. Para isso, é preciso que compreenda o processo lógico e histórico da construção do conceito a ser trabalhado, como também que organize esse jogo ou a situação com o jogo, levando em consideração que precisa propor ao estudante um problema de aprendizagem.

Ao fazermos menção sobre a situação problema, buscamos, em Rubtsov (1996), compreender dois tipos de conhecimentos que ele distingue: conhecimento teórico e conhecimento empírico. $\mathrm{O}$ conhecimento teórico é aquele que analisa o papel da função nas relações entre as coisas do interior de um sistema. Já o conhecimento empírico é aquele que compara dois objetos e suas relações concretas. Dessa forma, compreendemos que o conhecimento teórico é aquele que chamamos de científico e o conhecimento empírico é o conhecimento espontâneo. Organizar o ensino a partir de situações problemas a serem resolvidas, por exemplo, durante um jogo, poderá colocar o aluno na necessidade de apropriação de um conhecimento teórico, que consiste em aprender uma forma geral de ação, ou seja,

Essa resolução pede que um dado modelo de ação seja transformado em uma base, que constitui a orientação comum para completar as ações concretas relativas a uma classe de problemas; procedimento que resulta na transformação do aluno em si, através de uma autotransformação, uma vez que ele modifica, então, os modos de funcionamento e regulagem das suas próprias ações e adquire novos modos de orientação das suas ações no interior do sistema de situações que o cerca (RUBTSOV, 1996, p. 133).

Para que isso aconteça, não pode ser oferecido ao estudante um problema com uma solução imediata, e sim, um problema que envolva um plano de ação, a fim de que ele organize seu pensamento, buscando conhecimentos anteriores sobre o conceito, dialogando com o seu grupo, a fim de compreender esse processo e ampliar seu conhecimento do espontâneo para um conhecimento mais elaborado, o conhecimento teórico (MOURA, 1992). Novamente, aqui trazemos a potencialidade do jogo na organização do ensino por meio da AOE, pois nesse sentido, não tem caráter de exercício ou fixação de um conteúdo matemático que está sendo estudado, mas sim, como uma situação que motivada por uma necessidade de aprendizagem, possibilita o desenvolvimento das funções psicológicas superiores. 
Outro elemento importante, ao pensar no jogo, é sua característica lúdica e atrativa. Já compreendemos que o jogo ainda pode ser a atividade principal do estudante nos primeiros anos de vida escolar e que, por meio dele, pode interagir com o outro e com sua cultura, compreendendo o mundo em que está inserido e estabelecendo significados àquilo que vai se apropriando. Sabemos que o jogo pelo jogo não é promotor de aprendizagem, mas aquele que possibilita à criança interpretar seus conhecimentos anteriores e dialogar com seus pares, para que, de fato, se aproprie de determinado conteúdo. Agora, vale ressaltarmos a característica lúdica do jogo.

A ideia de que a matemática é uma disciplina difícil de aprender e ensinar já vem sendo muito discutida em educação, o que tem levado muitos educadores matemáticos a defender o uso de jogos, principalmente na educação infantil e nos anos iniciais, na perspectiva de tornar o ensino dessa disciplina mais atraente, divertido e lúdico. Corroboramos com a ideia de que o jogo poderá trazer novos sentidos à aprendizagem, modificando os motivos do fazer matemática das crianças e tornando o conhecimento cada vez mais elaborado. Contudo, reiteramos que, no jogo, é preciso ocorrer interação, pois só assim o professor conseguirá dar sentido humano a esse jogo e ao ensino de matemática.

\begin{abstract}
O jogo pode, ou não, ser jogo no ensino. Ele pode ser tão maçante quanto a resolução de uma lista de expressões numéricas: perde a ludicidade. No entanto, resolver uma expressão numérica também pode ser lúdico, dependendo da forma como é conduzido o trabalho. $O$ jogo deve ser jogo do conhecimento, e isto é sinônimo de movimento do conceito e de desenvolvimento (MOURA, 1992, p. 49).
\end{abstract}

Portanto, para que o jogo se configure como "jogo no ensino", é preciso que ele seja orientador da prática pedagógica, no sentido de que o ensino seja planejado intencionalmente, envolvendo situações em que os problemas sejam de aprendizagem e ele forneça à criança elementos em que ela atribua sentido e significado ao que vem sendo estudado, em especial aos conhecimentos matemáticos, e a AOE pode se constituir como esse modo geral de organizar o ensino de matemática nos anos iniciais do Ensino Fundamental.

A perspectiva do jogo como orientador da prática pedagógica conduziu-nos a uma pesquisa que intencionava investigar sobre o jogo no ensino das operações fundamentais nos anos iniciais do Ensino Fundamental. Especificamente neste artigo, reportaremo-nos a uma das situações de ensino relativas à essa investigação, que envolveu o conceito de multiplicação. Essa situação de ensino foi desenvolvida por participantes em formação inicial do GEPEMat. Nosso grupo tem se preocupado em estudar sobre o ensino e a aprendizagem de matemática, sobretudo, atentando à prática pedagógica na formação inicial e continuada. Dessa maneira, dele fazem parte, como já mencionamos, diferentes sujeitos que ocupam diferentes espaços na educação básica e superior e que têm em comum o interesse pela Educação Matemática na escola pública.

A situação de ensino situa-se no âmbito do projeto Clube de Matemática ${ }^{4}$, no qual nosso grupo estuda e desenvolve ações de ensino de matemática, em escolas da rede pública da cidade de Santa Maria/RS.

Como modo de avançar nas nossas discussões sobre o jogo como orientador da prática pedagógica, temos buscado compreender o processo da organização do ensino, tentando aproximar-se de um modo geral de organização por meio do jogo, alicerçado aos fundamentos teóricos da Atividade Orientadora de Ensino. Esse modo geral de ação está relacionado às etapas de organização do ensino que permitem ao professor proporcionar situações de ensino e aprendizagem, para que seus alunos se apropriem dos conhecimentos matemáticos, que vão além de exercícios de memorização para aqueles que desenvolvem o pensamento e formam uma nova qualidade nas funções psíquicas.

Nessa perspectiva, foi desenvolvida a situação de ensino a qual nos referimos, pautandose na Atividade Orientadora de Ensino, em uma turma de $4^{\circ}$ ano do Ensino Fundamental, de uma escola de periferia que tinha um grau elevado de dificuldade de aprendizagem, considerado àquem do esperado para esse ano de escolaridade. Seu planejamento envolveu quatros pontos

\footnotetext{
4 O projeto Clube de Matemática iniciou a partir de uma experiência realizada na Faculdade de Educação de São Paulo (USP). De 2011 a 2014 fez parte do projeto "Educação Matemática nos Anos Iniciais: Princípios e Práticas da Organização do Ensino" (OBEDUC/PPOE), desenvolvido em rede com a USP, USP de Ribeirão Preto, UFG e UFSM, coordenado pelo Prof. Manoel Oriosvaldo Moura. Altamente é desenvolvido pelo Grupo de Estudos e Pesquisas em Educação Matemática, da Universidade Federal de Santa Maria (GEPEMat/UFSM), financiado pela Coordenação de Aperfeiçoamento de Pessoal de Nível Superior (CAPES).
} 
que consideramos como fundamentais na organização do ensino, conforme já citamos: estudo, organização das ações, registro e avaliação.

$\mathrm{O}$ primeiro ponto a que nos referimos é o referente à síntese histórica do conceito. O conceito é aqui entendido como histórico, como produto de necessidades humanas criadas com o objetivo de satisfazer necessidades. Ou seja, as necessidades sentidas no desenvolvimento histórico da humanidade permitiram a elaboração dos conceitos que hoje fazem parte da nossa herança cultural.

A multiplicação é um conceito histórico elaborado historicamente a partir da necessidade humana de controlar quantidades, constituindo-se como simplificação da adição, que por sua vez é simplificação da contagem. A necessidade de contagem mais rápida e eficiente é perceptível no desenvolvimento da humanidade quando para controlar grandes quantidades com eficiência já não era mais suficiente a contagem a partir da correspondência um a um ou por agrupamentos. Tornouse essencial criar uma forma mais rápida e precisa que resolvesse situações que possibilitassem este cálculo. Dessa forma, a necessidade de agilizar a contagem desencadeia um processo mais rápido, a adição. Posteriormente, a adição já não era mais suficiente, fazendo-se necessário um processo mais rápido ainda, chegando à multiplicação. A contagem por meio da multiplicação envolve ações mentais que consideramos basilares que os alunos se apropriem: soma de parcelas iguais, organização em linhas e colunas (configuração retangular) e combinação de elementos.

A partir do princípio de que a multiplicação é um movimento das quantidades que facilita a contagem, passamos à organização das ações que seriam desenvolvidas com as crianças, sendo que trataremos aqui das referentes à ação mental de soma de parcelas iguais, desencadeadas a partir de uma situação uma situação de ensino que envolveu três jogos: Roleta da Multiplicação, Jogo do Boliche e Chute ao Gol. Estes foram organizados e construídos pelos participantes do grupo, no qual, preocupou-nos em trazer na situação com o jogo, a ação mental da soma de parcelas iguais que seria desencadeada a partir da necessidade dos alunos controlarem quantidades referentes aos pontos obtidos no jogo.

O jogo da Roleta da Multiplicação consistia em uma roleta dividida em quatro partes e, em cada uma delas, uma quantidade de palitos: dois, três, quatro e cinco. Foram distribuídos seis copinhos de café, canudinhos e um quadro de registros para cada aluno anotar sua pontuação. Para jogar, o estudante deveria lançar um dado para obter o número de copos que utilizaria no jogo. Depois era necessário girar a roleta para saber o número de canudinhos que deveria colocar em cada copo. Cada criança deveria registrar o número total de canudos que colocava nos copos.

O outro jogo, chamado de Jogo do Boliche, foi construído com 10 garrafas pet de $600 \mathrm{ml}$, cada uma contendo três bolinhas de gude. Ao jogar, o estudante deveria arremessar uma bola para derrubar as garrafas. Depois, deveria registrar o número de pontos, que era determinado pela quantidade total de bolinhas de gude das garrafas derrubadas.

O terceiro jogo, Chute ao Gol, foi realizado na quadra de esportes da escola. Para jogar, cada estudante poderia chutar uma bola de futebol de salão quatro vezes e, em cada uma dessas quatro jogadas, teria a possibilidade de três chutes. Cada aluno deveria registrar a sua pontuação, levando em consideração que cada gol feito valia seis pontos.

Compreendendo que o trabalho do professor na educação escolar é organizar o ensino com intencionalidade, ao trabalhar com o conceito de multiplicação tivemos como intenção que as crianças conseguissem:

1) compreender que uma das ações mentais da multiplicação está relacionada a soma das parcelas iguais;

2) perceber que contabilizar os pontos por agrupamentos é mais rápido do que contar de um em um;

3) compreender que, na multiplicação de dois fatores, o primeiro indica quantas vezes o segundo se repete;

4) entender que, para controlar grandes quantidades, não é suficiente realizar a contagem de um em um, ou por agrupamentos, sendo necessário utilizar a multiplicação.

Aliado a essas intenções, estava nosso objetivo geral dos jogos que era propiciar que os estudantes compreendessem a necessidade humana e histórica em elaborar o conceito de multiplicação, percebendo que controlar grandes quantidades, contando de um a um ou por agrupamentos, não é mais suficiente, sendo necessário realizar a contagem através da multiplicação. 
Nesse sentido, compreendemos a potencialidade do jogo como uma situação desencadeadora de aprendizagem na perspectiva da AOE quando este pressupõe - a partir da intencionalidade do professor ao organizar o ensino - que promova nos estudantes a apropriação de conhecimentos e das experiências humanas ao longo da história. Para Moura, Sforni e Lopes (2017) essa apropriação só é possível quando o problema que desencadeará a aprendizagem trouxer a essência da necessidade que levou a humanidade a criar o conceito a ser ensinado, chegando a uma solução que irá contemplar também a forma como os homens foram se organizando para satisfazer essa necessidade.

A situação desencadeadora de aprendizagem deve, ainda, ter o potencial para propiciar o aparecimento do motivo da aprendizagem, para desencadear a tensão criativa dos processos de aprendizagem no sujeito que se organiza para se apoderar de um conceito que considera relevante para si. Está é a essência da situação desencadeadora de aprendizagem. (MOURA, SFORNI, LOPES, 2017, p. 91-92)

Assim, ao organizar situações desencadeadoras de aprendizagem por meio da AOE, em especial, utilizando o jogo, a preocupação foi trazer na situação com o jogo a essência do conceito de multiplicação, ou seja, que as crianças sentissem a necessidade em contabilizar os pontos utilizando uma das ações mentais que compõe o conceito de multiplicação, que no caso dos três jogos, esteve relacionado a soma de parcelas iguais.

A dinâmica que adotamos para sistematização desse processo de vivenciar os três jogos foi na perspectiva de circuito. Em cada um desses jogos havia um participante do grupo (professor ou futuro professor) que estava encarregado de apresentar e desenvolver a situação do jogo com um grupo de crianças. Por sua vez, a turma de alunos foi dividia em três grupos, dessa forma, todos estavam em situações com o jogo e todos vivenciaram os três modos de se realizar multiplicação. Em cada um deles, o grupo jogava, registrava e discutia quem tinha conseguido mais pontos. Os integrantes do grupo de pesquisa fizeram seus registros por meio de fotografias e de diários.

Ao defendermos o jogo como um elemento com potencialidade pedagógica de desenvolvimento do pensamento, compreendemos esse como essencial no processo de formação e educação da criança. Assim, o jogo pode configurar-se como uma atividade que permite à criança se relacionar com seus pares, apropriando-se de conhecimentos teóricos e desenvolvendo capacidades psíquicas que permitirão à criança viver em sociedade. Mas apenas propiciar situações com jogos é suficiente para a criança desenvolver o pensamento teórico e se apropriar do conhecimento que está sendo estudado? Acreditamos que somente isso não é suficiente para propiciar a aprendizagem. Por isso, e também na perspectiva que adotamos, faz-se necessário propormos problemas desencadeadores de aprendizagem. Estes problemas precisam mobilizar a organização do pensamento, a avaliação das ações, a troca entre os pares, para depois, chegar-se a síntese coletiva.

Diante do exposto, foram apresentadas para as crianças três questões mobilizadoras para a discussão, que sintetizavam a situação desencadeadora relacionada a como contar de forma mais rápida e eficiente possível os pontos obtidos nos jogos.

1) Como vocês descobriram o número de pontos em cada jogo?

2) De que forma foi feita a contagem?

3) Que outra maneira, mais rápida e eficiente, poderíamos utilizar?

$\mathrm{Na}$ primeira questão, as crianças responderam usando como exemplo o Jogo do Boliche, indicando que o cálculo levou em consideração a quantidade de pinus (garrafas pet) derrubados e o número de bolinhas que havia em cada garrafa. Isso nos indicou que eles já conseguiam fazer a relação entre os dois fatores a serem multiplicados: a quantidade de garrafas $x$ a quantidade de bolinhas em cada uma delas.

Ao nos referirmos à forma de contagem, com a intenção de que explicitassem melhor o modo como resolveram a situação do jogo, as crianças apresentaram como possibilidade de contar os pontos obtidos a adição de parcelas iguais. Assim, no caso de uma delas que derrubou quatro pinos, sendo que em cada um tinha três bolinhas de gude, o cálculo foi feito da seguinte forma: $3+3+3+3$.

A discussão com as crianças, a partir das diferentes situações vivenciadas por elas nos três jogos, permitiu-nos explorar o conceito de multiplicação por parcelas iguais, na perspectiva de que poderia representar uma forma mais rápida e eficiente de chegar ao resultado. Além disso, 
também discutimos o significado que cada um dos fatores assumia na multiplicação. A necessidade dos alunos, posta pelo jogo, de chegar à contagem rápida dos pontos, motivou-os à compreensão dessa nova forma de realizar contagem, pois, a compreensão de que uma forma é mais eficiente que a outra, aponta indícios de que a ação de jogar pode ter se constituído como uma atividade de aprendizagem que produziu novas qualidades ao pensamento, passando de um conhecimento inicial para um conhecimento mais elaborado.

A partir dessa situação apresentada, compreender o papel do jogo significa compreender que a socialização é essencial no processo de desenvolvimento humano, ou seja, é a partir da inserção do sujeito com a cultura e da relação com o outro, que ele aprende e se desenvolve. E o jogo pode ser um meio da criança interagir com o mundo, com a cultura e com seus pares, apropriando-se dos conhecimentos historicamente elaborados pela humanidade. É a partir desse sentido que o jogo passa a ter um papel fundamental na vida da criança principalmente, na escola.

Defender o jogo como um importante recurso para o ensino e a aprendizagem de matemática na escola implica impregná-lo de intencionalidade pedagógica, de modo a constituir-se como orientador da prática docente. Ao organizar a situação de aprendizagem por meio do jogo, tivemos a preocupação de envolver a necessidade histórica de criar o conceito de multiplicação, apresentando uma intencionalidade clara em todas as situações propostas com os três jogos, e essa forma de organizar o ensino e de problematizar as situações desencadeadoras de aprendizagem só foi possível a partir da compreensão de que a AOE se constitui como um modo geral e especial de ensinar e aprender matemática, considerando o movimento do estudo, de organização e desenvolvimento das ações, do registro e da avaliação.

Salientamos que acreditamos que a crescente complexidade de cada jogo (que foi sendo desenvolvido ao longo das ações do projeto) permitiu aos estudantes um avanço qualitativo em sua compreensão sobre o conceito de multiplicação, no qual foram sentindo necessidade de formas mais elevadas de pensamento e organização de ações que solucionassem o problema, de forma rápida e eficiente, como trouxera a própria síntese histórica da multiplicação. Quando a criança passa de um nível mental para outro, sua forma de interagir e de compreender esse jogo se altera, e é por isso que a necessidade de jogos cada vez mais complexos é exigida. Para tanto, o jogo precisa ser organizado de modo a aproximar a criança do conceito científico e, de acordo com os estudos da Teoria Histórico-Cultural, esse jogo precisa conter situações problemas próximas daquelas que a humanidade vivencia ou vivenciou ao longo do desenvolvimento de sua história.

Podemos perceber nas situações desencadeadoras que foram desenvolvidas com os três jogos: jogo do boliche, jogo do chute ao gol e jogo da roleta, a complexidade do pensamento em contabilizar os pontos obtidos em cada um dos jogos. Pois, quando a criança começa a ter de resolver o problema proposto de uma forma mais abstrata, como foi evidenciado no jogo do chute ao gol, do qual não havia suporte concreto, ela avança para um conhecimento mais elaborado e começa a compreender a essência do conceito de multiplicação. Lanner de Moura et al (2016, p.301 expressam que

\footnotetext{
Matemática não é contagem; é, ao contrário, a abstração da contagem, tanto quanto o número é a abstração da pedrinha (do cálculo) e do algoritmo.[...] Abstrair não é ignorar; é conhecer profundamente um processo, a ponto de produzir modelos mentais, com base nele sem recorrer à sua concretude.
}

Cabe ressaltar que, mesmo tempo em que a criança ocupa papéis diferentes no jogo, à medida que ele vai se tornando mais complexo, o papel do professor na organização do ensino e na proposição de situações com o jogo também se altera. Ou seja, é aqui que o professor poderá avaliar o nível de impacto causado ao propor determinada situação, reorganizando-a de um modo que melhor atenda a seu objetivo: a apropriação da aprendizagem pelos estudantes.

Além disso, também é importante destacar o modo como os jogos foram encaminhados pelos participantes da pesquisa para as crianças. O jogo precisa desafiar os jogadores e instigá-los a jogar, a descobrir, a explorar e a trocar conhecimentos espontâneos com seus pares, resultando em conhecimentos científicos. Ou seja, o movimento do jogo, a interação, a mediação e os encaminhamentos precisam elevar o nível de desenvolvimento e de compreensão do conceito estudado. 
Desse modo o jogo tem relevante papel como atividade que pode favorecer o desenvolvimento da criança quando ele está carregado da essência de determinado conceito. Para Moura (1997), para que o jogo se torne uma potência para aproximar a criança do conhecimento científico, deve levá-la a vivenciar "virtualmente" situações nas quais possa solucionar problemas que a aproximem daqueles que o homem enfrentou ou enfrenta efetivamente na sua vida em sociedade e, para que isso ocorra, a intencionalidade do professor é determinante.

Por tratar-se de ação educativa, ao professor cabe organizá-la de forma que se torne atividade que estimule auto-estruturação do aluno. Desta maneira é que a atividade possibilitará tanto a formação do aluno como a do professor que, atento, aos "erros" e "acertos" dos alunos, poderá buscar o aprimoramento do seu trabalho pedagógico. (MOURA, 1997, p.85).

A avaliação das ações desenvolvidas aponta-nos indícios de que os três jogos proporcionaram uma situação de aprendizagem para as crianças, à medida que, a partir de suas falas e seus registros, conseguimos identificar compreensões que, sozinhas, sem a interação e a mediação com outro mais experiente, provavelmente não iriam ocorrer. Como já discutimos anteriormente, consideramos que por meio do jogo as crianças entram em contato com sua cultura e se apropriam dos conhecimentos elaborados ao longo do desenvolvimento da humanidade. As questões lançadas pelos pesquisadores visando uma síntese de solução coletiva, levou as crianças a expressarem todas as maneiras que utilizaram para contabilizar os seus pontos, que, embora diferentes, envolveram uma aprendizagem comum: a apropriação do conceito de multiplicação.

Podemos identificar possíveis aprendizagens do conceito matemático a partir do momento em que o grupo dialogou e aqueles que ainda não haviam compreendido, organizaram seu pensamento na direção de que contabilizar os pontos utilizando a multiplicação, que era mais rápido e eficiente. Esta compreensão mostrou-nos indícios de apropriação do conceito estudado, na medida em que o jogo provocou uma reorganização mental, tornando aquele conhecimento mais elaborado.

Em relação aos professores e aos futuros professores envolvidos, salientamos que a avaliação sobre os encaminhamentos e as hipóteses trazidas pelas crianças foram de extrema relevância, uma vez que a unidade entre a teoria adotada e os encaminhamentos realizados foi preponderante para a organização das situações de aprendizagens seguintes e na ratificação de que o jogo pode se constituir como ser orientador da prática pedagógica a partir dos pressupostos da AOE.

\section{A INTENCIONALIDADE PEDAGÓgICA DO JOGO COMO ORIENTADOR DA PRÁTICA PEDAGÓGICA: algumas considerações}

De acordo com o Leontiev (1988), dizer que o jogo é a atividade principal da criança não significa dizer que ele é a sua atividade predominante. Nesse sentido, é que defendemos que, para as crianças nos anos iniciais, embora tenham como atividade principal o estudo, o jogo ainda está presente em sua forma de compreender o mundo e a realidade. Portanto, entendemos que ele pode contribuir para a aprendizagem e desenvolvimento para as crianças que já avançaram um nível acima da pré-escolar.

Nesse sentido, ele torna possível para a criança concretizar suas necessidades de se relacionar com os objetos e com os seus pares que fazem parte do seu grupo, produzindo novos sentidos a partir dessa interação. As relações estabelecidas durante o jogo permitem que a criança estruture e organize sua atividade desde o estabelecimento de objetivos para o professor e também para ela. Em relação ao primeiro, como já evidenciamos, a característica de propiciar a organização da prática pedagógica e, em relação ao segundo, a compreensão do mundo adulto e a apropriação da cultura mais elaborada.

As questões discutidas, ao longo da escrita desse artigo, permitem-nos refletir em que medida o jogo poderá se constituir como orientador da prática pedagógica, a partir dos pressupostos da Atividade Orientadora de Ensino e, mais especificamente no que se refere ao processo de ensino e aprendizagem da matemática. Nesse sentido, apontamos alguns elementos que destacamos como organizadores gerais, ou seja, para que o jogo se configure como orientador da prática pedagógica e da atividade de aprendizagem, na perspectiva da AOE, entendemos como importante que:

- desperte nos estudantes necessidades de aprendizagens matemáticas;

- seja atrativo, tanto em seu aspecto físico, quanto na provocação do ato de jogar; 
- em seu desenvolvimento o aspecto lúdico esteja presente;

- possibilite a interação com os demais jogadores;

- contenha um aumento de grau de complexidade de conteúdo;

- contemple a essência do conceito matemático como problema a ser resolvido;

- seja acompanhado de registros, para que o estudante organize seu pensamento e suas ações;

- a situação com o jogo seja planejada de forma organizada e intencional visando a aprendizagem matemática do estdante.

Diante do exposto, ratificamos que o jogo, desprovido da intencionalidade do professor, não pode se constituir como orientador da prática pedagógica, tampouco, levar à aprendizagem das crianças. É preciso que seja organizado direcionando uma nova qualidade, seja da ação do professor, seja do conhecimento do aluno.

Relembramos, ainda, a importância do aspecto lúdico impregnado no jogo, pois a fantasia, vivenciada na e pela situação de jogar, permitirá que a criança se humanize, pois é por meio da apropriação da cultura humana que se dá o desenvolvimento das funções psicológicas superiores.

Em relação à prática pedagógica, corroboramos com Lopes (2009) que diz que "a aprendizagem do professor passa pela apropriação de conhecimentos docentes relevantes na medida em que possam contribuir para a compreensão e o melhor desenvolvimento da docência. (p. 75)". Ou seja, acreditamos que, para ensinar, é preciso estudar, e essa compreensão foi fundamental para a organização das ações que aqui apresentamos, principalmente quando acreditamos e defendemos que esse movimento é possível por meio de Atividades Orientadoras de Ensino em cujos princípios encontra-se a importância do conhecimento matemático como elemento que faz parte da cultura humana mais elaborada.

Desse modo "aprender a ser professor e, particularmente, aprender a ensinar Matemática passa por deparar-se com o desafio e a necessidade de organizar o ensino para favorecer a aprendizagem das crianças" (MORETTI, 2011, p. 387). Aprender a ser professor é um movimento constante, que envolve partilha e compartilhamento construídos na relação com outros pares, o que nos leva a vislumbrar o espaço do grupo de pesquisa como privilegiado também para o estudante em formação inicial aprender sobre a docência e a organização do ensino.

Finalizando, destacamos que considerar a possibilidade de organizar o ensino de matemática nos anos iniciais do Ensino Fundamental, utilizando o jogo, é compreender que, por meio dele, é possível promovermos relações humanas, desenvolvimento do pensamento teórico e novas qualidades psíquicas. Isso nos permite afirmar que, ao adotar o jogo como orientador da prática pedagógica, o professor poderá dar novos sentidos à sua atividade e apresentar um modo de ensinar matemática, usando o jogo não como instrumento, mas como potencializador do desenvolvimento de das funções psíquicas superiores, e isso ficou evidente a partir da organização do ensino com o jogo pautada nos princípios da Atividade Orientadora de Ensino. 


\section{REFERÊNCIAS}

DAVÍDOV, V. La enseñanza escolar y el desarrollo psiquico. Tradução de Marta Shuare. Moscú: Progreso, 1988.

ELKONIN, D. B. Psicologia do Jogo. Tradução: Álvaro Cabral. São Paulo: Martins Fontes, 1988.

KOPNIN, P. V. A dialética como lógica e teoria do conhecimento. Rio de Janeiro: Civilização Brasileira, 1978.

LANNER DE MOURA, M.R. et al. Educar com a Matemática: fundamentos. São Paulo: Cortez, 2016.

LEONTIEV, A. N. Os princípios psicológicos da brincadeira pré-escolar. In: VIGOSTKII, L.S.; LURIA, A. R. Linguagem, desenvolvimento e aprendizagem. Tradução: Maria da Pena Villalobos. 12 ed. São Paulo: Ícone, 2014.

La importancia del concepto de actividad objetal para la psicologia. In: Las funciones psicológicas en el desarrollo del niño. México: Trillas, 2009.

Uma contribuição à teoria do desenvolvi$\overline{\text { mento }}$ da psique infantil. In.: VIGOTSKII, L.S.; LURIA, A.R. \& LEONTIEV, A.N. Linguagem, desenvolvimento e aprendizagem. 5ed. São Paulo: Ed. Ícone, 1988. p.59-83

. Actividad, Conciencia e Personalidad. Havana: Editorial Pueblo y Educacion, 1983.

O desenvolvimento do psiquismo. Lisboa: Horizonte Universitário, 1878.

LOPES, A. L. V.; VAZ, H. G. B. O Movimento de Formação Docente no Ensino de Geometria nos Anos Iniciais Educação \& Realidade, v. 39, n. 4, oct./ dic, 2014, p. 1003-1025, Universidade Federal do Rio Grande do Sul Porto Alegre, Brasil. Disponível em: < http://www.scielo.br/pdf/edreal/v39n4/04.pdf> Acesso em: 04 de Out. 2017.

LOPES, A. R. L. V. Aprendizagem da docência em matemática: o Clube de Matemática como espaço de formação inicial de professores. Passo Fundo: Ed. Universidade de Passo Fundo, 2009.

MORETTI, V. D. A articulação entre a formação inicial e continuada de professores que ensinam matemática: o caso da Residência Pedagógica da Unifesp. Revista eletrônica de Educação: Porto Alegre, v. 34, n. 3, p. 385-390, 2011. Disponível em: <http:// revistaseletronicas.pucrs.br/ojs/index.php/faced/article/viewFile/7733/6789>. Acesso em: 05 nov. 2017.

MOURA, M. O. (Org.). A atividade pedagógica na teoria Histórico-Cultural. Brasília: Líber livro, 2010.

MOURA, M. O. de. Matemática na infância. In: MIGUEIS, M. R.; AZEVEDO, M. G. (Orgs.). Educação matemática na infância: abordagens e desafios. Serzedo (Portugal): Gailivro, 2007. p. 39-64.

. $O$ educador matemático na coletividade de formação: uma experiência com a escola pública. Tese apresentada à Faculdade de Educação da Universidade de São Paulo - USP. 2000.

A séria busca no jogo: do lúdico na matemática. In: KISHIMOTO, T. M. (Org.). Jogo, brinquedo, brincadeira e a educação. 2 ed. São Paulo: Cortez, 1997.

A atividade de ensino como unidade formadora. Bolema, Rio Claro, v. 12, p.29-43. 1996.

O jogo e a construção do conhecimento matemático. Série Idéias n. 10, São Paulo: FDE, p. 45-53. 1992. Disponível em: <http://www.crmariocovas.sp.gov.br/pdf/ideias_10_p045-053_c.pdf> Acessado em: 05 de nov. de 2017.

MOURA, M. O. de. et al. A atividade orientadora de ensino como unidade entre ensino e aprendizagem. In: MOURA, M. O. (ORG) A atividade pedagógia na teoria Histórico-Cultural. Brasília: Líber livro, 2010.

MOURA, M.O.; SFORNI, M.S.F.; LOPES, A.R.L.V.. A objetivação do ensino e o desenvolvimento do modo geral da aprendizagem da atividade pedagógica. In: MOURA, M.O. (Org.). Educação escolar e pesquisa na teoria histórico-cultural. São Paulo: Edições Loyola, 2017.

NASCIMENTO, C. P. ;ARAÚJO, E.S.; MIGUEIS, M. O jogo como atividade: contribuições da teoria histórico-cultural. Revista Semestral da Associação Brasileira de Psicologia Escolar e Educacional (ABRAPEE) . v. 13, n. 2, jul./dez., p 293-302. 293. 2009.

RUBTSOV, V. A atividade de aprendizagem e os problemas referentes à formação do pensamento teórico dos escolares. In: GARNIER, C. et al. (Org). Após Vygotsky e Piaget: perspectiva social e construtivista. Escola russa e ocidental. Tradução Eunice Gruman. Porto Alegre: Artes Médicas, 1996.

VIGOTSKII, L.S. Aprendizagem e desenvolvimento intelectual na idade escolar. In: VIGOSTKII, L.S.; LURIA, A. R. Linguagem, desenvolvimento e aprendizagem. Tradução: Maria da Pena Villalobos. $12^{\circ}$ edição. São Paulo: Ícone, 2014.

VYGOTSKY, L.; S. Aprendizagem e desenvolvimento intelectual na idade escolar. In: LEONTIEV, A. N. et al. Psicologia e Pedagogia: bases psicológicas da aprendizagem e do desenvolvimento. Tradução de Rubens Eduardo Farias. São Paulo: Centauro, 2005. 